\title{
Prevalence of intestinal parasitic infections among people living with HIV/AIDS visiting a central hospital of Kathmandu Nepal
}

\author{
Homa Nath Sharma ${ }^{1}$, Bimal Sharma Chalise ${ }^{2}$, Ganesh Rai ${ }^{3}$, Nabaraj Adhikari ${ }^{4}$, \\ Anup Bastola ${ }^{5}$, Anjana Singh ${ }^{6,7}$ \\ ${ }^{1}$ Principal Investigator/Microbiology Graduate, Central Department of Microbiology, Tribhuvan University, Kirtipur, \\ Kathmandu, Nepal, ${ }^{2,5}$ Senior Consultant, Sukraraj Tropical and Infectious Disease Hospital, Teku, Kathmandu, Nepal, \\ ${ }^{3}$ Lecturer, Shi-Gan International College of Science and Technology, Narayangopalchowk, Maharajgunj, Kathmandu, \\ Nepal, ${ }^{4}$ Lecturer, Kantipur College of Medical Sciences, Sitapaila, ${ }^{6}$ Former Head, Central Department of Microbiology, \\ Tribhuvan University, Kirtipur, Academician, Nepal Academy of Science and Technology, Satdobato, Lalitpur, \\ Kathmandu, Nepal
}

A B S T R A C T

Backgrounds: Intestinal Parasitic Infection (IPI) plays a vital role in the prognosis of People Living with HIV/AIDS (PLHA). Aims and Objectives: In this study, we aimed to measure the prevalence and associated factors of IPI among PLHA and non-HIV patients attending Sukraraj Tropical and Infectious Disease Hospital, Teku, Kathmandu. Materials and Methods: A cross-sectional study was conducted among 193 PLHA and 111 non-HIV patients having either of gastrointestinal disorders. Direct smear, Formalin ethyl acetate sedimentation and Kinyoun's modified acid fast staining methods were applied to detect intestinal parasites from stool samples and $\mathrm{CD}_{4} \mathrm{~T}$-cell counts of PLHA was recorded from ART centre of hospital. Results: The overall prevalence of IPI was found to be $16.12 \%(19.17 \%$ in PLHA and $10.81 \%$ in non-HIV subjects). Prevalence was higher in PLHA $(p<0.06)$ in which poly parasitic infection was common $(24 \%)$ with the protozoa predominating over helminths. $C_{4}$ T-cell counts $<200 / \mu \mathrm{l}(\mathrm{p}<0.06)$ and diarrhoea $(p<0.06)$ were associated with increased IPI in PLHA. Cryptosporidium parvum was found in $19.05 \%$ cases of PLHA having $\mathrm{CD}_{4} \mathrm{~T}$-cell counts $<200 / \mu \mathrm{l}$. Conclusions: The higher prevalence of opportunistic protozoa among PLHA indicates the need of routine parasitic investigation using sensitive methods so that it will be helpful for the proper therapeutic management.

Key words: PLHA, ART, IPI, CD 4 T-cell counts
http://nepjol.info/index.php/AJMS DOI: 10.3126/ajms.v8i5.17731 E-ISSN: 2091-0576 P-ISSN: 2467-9100

\section{INTRODUCTION}

HIV/AIDS has become one of the most devastating infectious diseases to have been emerged in recent history. ${ }^{1}$ Similarly Intestinal Parasitic Infections (IPI) is endemic worldwide and has been described as contributing the greatest single worldwide cause of illness and disease. ${ }^{2}$ IPI plays a vital role in the prognosis of People Living with HIV/AIDS (PLHA). ${ }^{3}$ It's endemic in many developing countries of Asia and Africa due to poor sanitation, poor hygiene and unavailability of safe drinking water. ${ }^{4}$ Diarrhoea is a common gastrointestinal symptom in HIV positive patients occurring in more than $90 \%$ of patients in developing countries and 30-60\% of patients in developed countries. It is an independent indicator of mortality and morbidity in PLHA. ${ }^{5}$ Almost $80 \%$ of AIDS patients die from AIDS-related infections including intestinal parasites rather than HIV infection itself. ${ }^{6}$ Several intestinal parasites previously considered non-pathogenic or with transient pathogenic potential in immune competent individuals opportunistically become aggressive and cause debilitating illness in HIV / AIDS patients. ${ }^{7}$ If such co-infections is not diagnosed and prognoses properly, dramatically enhance the more rapid progression to AIDS, as a result of more rapid decline of the $\mathrm{CD}_{4} \mathrm{~T}$-lymphocytes count which characteristically falls below $200 / \mu 1 .^{8}$ 
In Nepal, cumulative reported HIV positive cases were found $28865^{\circ}$ and PLHIV currently on ART was 12,446 in July $2016 \cdot{ }^{10}$ It has been estimated that there are more than 60,000 PLHA in Nepal. ${ }^{4}$ Similarly, IPI is highly prevalent among the general population of Nepal. ${ }^{11} \mathrm{It}$ is alone one of the most common public health problem in all over Nepal. ${ }^{12}$ In 2011, in hospital visiting patients, it was $21.4 \%{ }^{13}$ and in the people included in a survey was $15.17 \% .{ }^{11}$ Previous studies among PLHA in Nepal have reported high prevalence of intestinal parasitic infections. It was reported $26.7 \%$ in $2006^{14}$ and $22.4 \%$ in $2008 .{ }^{4}$ Lower $\mathrm{CD}_{4}$ T-cell counts; diarrhea; sex and some other factors were associated with increased IPI among PLHA. ${ }^{4}$

IPI creates a huge concern in the management and care of PLHA. Detecting these parasite and understanding the status and significance of the infection they cause will greatly help in proper therapeutic management of these people and will prevent further infection. ${ }^{3}$ This study was to determine prevalence of IPI in PLHA and to compare with those infections in non-HIV patients in the regard of age, gender and diarrheal status. It was also to compare the IPI among PLHA currently under Antiretroviral therapy- ART (On ART PLHA) and not currently under ART (ART naïve PLHA) as well as among PLHA having $\mathrm{CD}_{4}$ T-cell count $<200 / \mu \mathrm{l}$ and $\geq 200 / \mu \mathrm{l}$.

\section{MATERIALS AND METHODS}

Study was conducted from September, 2016 to February, 2017 in Sukraraj Tropical and Infectious Disease Hospital, Teku, Kathmandu, from which majority (about 1500) of PLHA and general patients of Kathmandu and from almost all parts of Nepal take regular health services. Being one of the largest governmental hospitals, it is accessible and affordable for all people in need.

Combined (Both qualitative and quantitative) research method was applied for cross-sectional study that was performed in PLHA and non-HIV subjects, both subjects having either diarrhoea or any other gastrointestinal (GI) disorders like flatulence, abdominal cramp, constipation, vomiting and tenesmus. But both subjects would have been visited the hospital for their respective GI problems.

Purposive random sampling was applied with recruiting eligible patients. By assuring confidentiality and anonymity of their information, informed consent was taken from patients. Tight, leak proof, waterproof and wide mouthed container was provided to participants after informing about proper technique of stool sample collection. Then sample was taken from participant, questionnaire was filled up also with the help of record found in ART Centre of hospital, container was sealed by paraffin wax; kept in protective transport box and was duly transported to and processed in Microbiology lab of Shi-Gan International College of Science and Technology, Maharajgunj. In case of anticipation of delay in transport by more than 2 hours, $10 \%$ formalin was added for preservation of parasites in stools. Unpreserved samples were processed by saline wet mount for detecting any motile form. Iodine wet mount was applied for colour contrast of cell organelles of parasites. Samples were further processed with formalin-ethyl acetate sedimentation. Concentrated deposits were observed by microscopy for different form of parasites that might be missed in direct wet mount. Centrifuged deposits were also processed by Kinyoun's Modified (cold) acid fast staining for oocyst of coccidian. ${ }^{15}$

Data management, processing and analysis

Data maintained in the computer sheets was organized and analysed by using SPSS software for Windows IBM 20. A value of $\alpha \leq 0.06$ was assumed and $94 \%$ confidence interval (CI) along with the exact $\mathrm{p}$-value was presented.

\section{RESULTS}

A total of 304 stool specimens (193 from PLHA and 111 from non-HIV patients) were processed for the detection of intestinal parasites. Out of total PLHA, 97 (50.26\%), $92(47.67 \%)$ and $4(2.07 \%)$ were male, female and transgender (TG) respectively while of the total non-HIV patients, 54 (48.65\%) and $57(51.35 \%)$ were male and female respectively. Age of PLHA ranged from 7-59 years with mean age 30.29 years and of the non-HIV patients age ranged from 6-65 years with mean age 28.45 years. $116(60.1 \%)$ and $73(65.77 \%)$ were diarrheal patients among PLHA and non-HIV patients respectively while remaining were having other GI disorder. Among PLHA, 125 (64.77\%) were On ART PLHA and $68(35.23 \%)$ were ART naive PLHA. Out of 193 PLHA, $21(10.88 \%)$ and $172(89.12 \%)$ were belonged to having $\mathrm{CD}_{4}-\mathrm{T}$ cell count $<200 / \mu \mathrm{l}$ and $\geq 200 / \mu$ respectively.

The overall prevalence of IPI was found to be $16.12 \%$ (19.17\% (37/193) in PLHA and 10.81\% (12/111) in non-HIV patients, $\mathrm{p}<0.06$ ). Prevalence was found highest in age groups $\leq 15$, followed by age group $\geq 36$ among study population. Prevalence was found higher in female than male and it was highest in transgender (TG) among PLHA. But it was higher in male than in female among non-HIV patients. Prevalence of IPI among PLHA having diarrhoea was significantly higher than that in subjects having other GI disorders but difference was insignificant among non-HIV patients (Table 1).

Entamoeba histolytica was predominant intestinal parasite found among study population followed by Giardia lamblia. Hookworm and Enterobius vermicularis were common among both PLHA and non-HIV patients. Entamoeba coli, Hymenolepsis 


\begin{tabular}{|c|c|c|c|c|c|c|c|c|c|c|}
\hline \multirow{2}{*}{$\begin{array}{l}\text { Study } \\
\text { population }\end{array}$} & \multicolumn{5}{|c|}{ PLHA } & \multicolumn{5}{|c|}{ Non-HIV patients } \\
\hline & $\begin{array}{c}\text { Parasite } \\
\text { positive } \\
\text { n (\%) }\end{array}$ & Total $\mathbf{n}$ & OR $(94 \% \mathrm{Cl})$ & $p$-value & $\begin{array}{c}\text { Chi-square } \\
\text { value }\end{array}$ & $\begin{array}{c}\text { Parasite } \\
\text { positive } \\
\text { n (\%) }\end{array}$ & Total $\mathbf{n}$ & OR $(94 \% \mathrm{Cl})$ & $p$-value & $\begin{array}{l}\text { Chi-square } \\
\text { value }\end{array}$ \\
\hline \multicolumn{11}{|l|}{ Age groups } \\
\hline$\leq 15$ & $2(100)$ & 2 & - & 0.02 & $9.801^{\mathrm{a}}$ & $3(100)$ & 3 & - & 0.000 & $30.567^{a}$ \\
\hline $16-25$ & $7(13.73)$ & 51 & & & & $3(7.5)$ & 40 & & & \\
\hline $26-35$ & $19(18.8)$ & 101 & & & & $2(3.9)$ & 51 & & & \\
\hline$\geq 36$ & $9(23.07)$ & 39 & & & & $4(23.53)$ & 17 & & & \\
\hline \multicolumn{11}{|l|}{ Sex } \\
\hline Male & 18 (18.56) & 97 & - & 0.942 & $0.121^{a}$ & $6(11.11)$ & 54 & - & 0.921 & $0.010^{\mathrm{a}}$ \\
\hline Female & $18(19.57)$ & 92 & & & & $6(10.53)$ & 57 & & & \\
\hline Trans gender & $1(25)$ & 4 & & & & $0(0)$ & 0 & & & \\
\hline \multicolumn{11}{|l|}{ Diarrheal status } \\
\hline Diarrhea & $29(25)$ & 116 & $\begin{array}{c}0.33 \\
(0.223-0.449)\end{array}$ & 0.012 & $6.375^{\mathrm{a}}$ & $9(12.33)$ & 73 & - & 0.475 & $0.510^{\mathrm{a}}$ \\
\hline $\begin{array}{l}\text { Other GI } \\
\text { disorder }\end{array}$ & $8(10.38)$ & 77 & & & & $3(7.89)$ & 38 & & & \\
\hline
\end{tabular}

nana, Cryptosporidium parvum, Taenia sp., Trichuris trichiura and Ascaris lumbricoides were found only among PLHA (Table 2).

Protozoa was found predominant over helminth among study population. Of the 37 IPI positive cases of PLHA, $75.68 \%(28 / 37)$ subjects revealed single intestinal parasites (16 protozoa and 12 helminths) in their stool. Remaining $24.32 \%(9 / 37)$ cases revealed more than one (poly) intestinal parasitic infection in single stool sample which was found mostly in PLHA having lower $\mathrm{CD}_{4}$ T-cell counts and associated with Entamoeba histolytica and Giardia lamblia infection (Table 2 and 3).

IPI was significantly higher in case of $\mathrm{CD}_{4}$ T-cell counts $<200 / \mu 1$ than in $\geq 200 / \mu$ l (Table 4). Cryptosporidium parvum, only one type of opportunistic intestinal parasite was found in $19.05 \%$ (4/21) subjects having $\mathrm{CD}_{4}$ T-cell counts $<200 / \mu \mathrm{l}$. Of the total 4 Cryptosporidium parvum positive cases, 3 were found singly and one was along with Entamoeba histolytica (Table 3). ART naive PLHA revealed higher prevalence than among On ART patients (Table 4).

\section{DISCUSSIONS}

The overall prevalence of IPI in this study was found to be $16.12 \%$ which is lower than that reported by previous studies which ranges from 15.17 to 31.5. ${ }^{11-14,16,17}$ Prevalence of IPI has been in decreasing trend in Nepal over two decade. ${ }^{13,16,18} \mathrm{It}$ ranges from $13.5 \%$ to $62.3 \%$ in the world. ${ }^{2,3,5-7,19-21}$ Such a huge difference may be associated with endemicity of parasite and sample size. ${ }^{4}$ Sanitary practice, level of education, economic status, social behaviour and differently selective cases are also attributed to the variation. ${ }^{22}$ IPI was significantly higher among PLHA. Similar result was found in India. ${ }^{22}$ Naturally PLHA have diminished level of immunity. ${ }^{2}$ Poverty striken

\begin{tabular}{|c|c|c|}
\hline \multirow[t]{2}{*}{ Intestinal parasites } & \multicolumn{2}{|c|}{ Intestinal parasite posiive $\mathrm{n}(\%)$} \\
\hline & In PLHA & In non-HIV patients \\
\hline Entamoeba histolytica & $11(23.91)$ & $6(50)$ \\
\hline Giardia lamblia & $9(19.57)$ & $3(25)$ \\
\hline Entamoeba coli & $6(13.04)$ & - \\
\hline Hymenolepsis nana & $5(10.87)$ & - \\
\hline Cryptosporidium parvum & $4(8.7)$ & - \\
\hline Hookworm & $3(6.52)$ & $2(16.67)$ \\
\hline Taenia sp. & $3(6.52)$ & - \\
\hline Trichuris trichiura & $2(4.35)$ & - \\
\hline Ascaris lumbricoides & $2(4.35)$ & - \\
\hline Enterobius vermicularis & $1(2.17)$ & $1(8.33)$ \\
\hline Total & $46(100)$ & $12(100)$ \\
\hline
\end{tabular}

*Cases associated with poly parasitic infection. Here, total positive cases exceed 37 due to poly parasitic infection among some PLHA

Nepalese PLHA are highly predisposed to any AIDS related infections. ${ }^{23}$ The prevalence of IPI among PLHA found in our study is lower than that reported earlier from elsewhere in Nepal ${ }^{4,14,24-26}$ and from developing countries of Africa and Asia. ${ }^{3,27-29}$ But, it is higher than that of the developed countries $^{30}$ and of some developing countries. ${ }^{31}$

Predomination of protozoa over helminth was in consent with previous studies. ${ }^{17,24}$ Time to time drug mass administration with albendazole could explain the low rate of helminthic infection. Entamoeba histolytica was found as the predominant intestinal parasite ranking Giardia lamblia in second position. It was in contrast to previous study in Nepal. ${ }^{16,32}$ and somewhere in the world ${ }^{33}$ but similar result was reported in Nigeria ${ }^{31}$ and Ethiopia. ${ }^{28}$ IPI was highest in age group $\leq 15$, followed by $\geq 36$ among PLHA and non-PLHA. Generally IPI abounds in developing countries with school children carrying the heaviest burden of the associated morbidity. ${ }^{34}$ Higher $(p>0.06)$ IPI was found in 


\begin{tabular}{|c|c|c|}
\hline Intestinal parasites & $\begin{array}{c}\text { Frequency in } \mathrm{CD}_{4} \text { T-cell } \\
\text { count }<200 / \mu \mathrm{ll}(\%) \\
\mathrm{n}=21\end{array}$ & $\begin{array}{c}\text { Frequency in } \mathrm{CD}_{4} \text { T-cell } \\
\text { count } \geq 200 / \mu \mathrm{l}(\%) \\
\mathrm{n}=172\end{array}$ \\
\hline Entamoeba histolytica & $2(9.5)$ & $3(1.74)$ \\
\hline Giardia lamblia & $2(9.5)$ & $3(1.74)$ \\
\hline Hookworm & - & $2(1.16)$ \\
\hline Hymenolepsis nana & $1(4.76)$ & $1(0.58)$ \\
\hline Trichuris trichiura & $1(4.76)$ & $1(0.58)$ \\
\hline Taenia sp. & $1(4.76)$ & $2(1.16)$ \\
\hline Cryptosporidium parvum & $3(14.29)$ & - \\
\hline Enterobius vermicularis & - & $1(0.58)$ \\
\hline Ascaris lumbricoides & $1(4.76)$ & $1(0.58)$ \\
\hline Entamoeba coli & - & $3(1.740$ \\
\hline Entamoeba histolytica and Entamoeba coli & $3(14.29)$ & - \\
\hline Entamoeba histolytica and Giardia lamblia & $1(4.76)$ & - \\
\hline Entamoeba histolytica and Hymenolepsis nana & $1(4.76)$ & - \\
\hline Entamoeba histolytica and Cryptosporidium parvum & $1(4.76)$ & - \\
\hline Giardia lamblia and hookworm & - & $1(0.58)$ \\
\hline Giardia lamblia and Hymenolepsis nana & - & $2(1.16)$ \\
\hline
\end{tabular}

\begin{tabular}{|c|c|c|c|c|c|}
\hline $\mathrm{CD}_{4} \mathrm{~T}$-cell counts & $<200 / \mu l n=21$ & $\geq 200 / \mu \mathrm{l} n=172$ & Chi-square value & OR (94\% CI) & $p$-value \\
\hline Intestinal parasite positive $\mathrm{n}(\%)$ & $17(80.95)$ & $20(11.63)$ & $58.043^{a}$ & $32.3(10.36-100.68)$ & 0.000 \\
\hline ART status & ART naive $n=68$ & On-ART $n=125$ & Chi-square value & OR $(94 \% \mathrm{Cl})$ & $\mathrm{p}$-value \\
\hline Intestinal parasite positive $\mathrm{n}(\%)$ & $15(22.1)$ & $22(17.6)$ & $0.565^{\mathrm{a}}$ & $0.283(0.163-0.491)$ & 0.452 \\
\hline
\end{tabular}

female than male among PLHA and more in male among non-HIV patients. Previous studies from Nepal indicate that sex is not the factor for acquisition of intestinal parasites. ${ }^{411}$ Much higher prevalence was observed in transgender PLHA. Oral-anal and oral genital contact predisposes homosexuals to infection with enteric pathogens. ${ }^{35}$

IPI was higher among PLHA having $\mathrm{CD}_{4}^{-} \mathrm{T}$ cell counts $<200 / \mu$ l than having $\geq 200 / \mu$ l, which shows agreements with reports from other countries regarding IPI in different $\mathrm{CD}_{4}$ ranges ${ }^{25,28,36,37}$ as well as from Nepal. ${ }^{4,38}$ In studies conducted in Nepal, more than three-fifth to four-fifth of the HIV patients with $\mathrm{CD}_{4}$ T-cell count $<200$ were found having parasitic infections. ${ }^{45}$ The present study revealed the detection of opportunistic parasite, Cryptosporidium parvum only among PLHA. This finding has been supported by other findings reported from Nepal and elsewhere in the world. ${ }^{4,24,26,29,33}$ Its $19.05 \%$ prevalence among PLHA having $\mathrm{CD}_{4}$ T-cell counts $<200$ cells/ $\mu \mathrm{l}$ was higher than previous study in Nepal24, 25, 32 and other countries. ${ }^{39}$ Most of those PLHA under our study had history of diarrhea and the prevalence rate of cryptosporidiosis among diarrheic HIV/ AIDS patients is usually found significantly higher than $10 \%{ }^{40}$ Cyclospora cayetanensis, Isospora belli and Microsporidia were also reported in previous study among immune-suppressed PLHA. ${ }^{24}$ Administration of co-trimoxazole to most of the adult PLHA whose $\mathrm{CD}_{4}$ T-cell counts decline to the threshold of $350 / \mu 1^{41}$ might have helped to prevent those infection because co-trimoxazole is effective to isospora and cyclospora infections. ${ }^{42,43}$ Isospora belli is more common in tropical and subtropical climate than in temperate climate. ${ }^{5}$ Prevalence of Cyclospora infection may be influenced by study design, geographic area, age, immunologic status of population studied and seasonal variability of parasite. ${ }^{44}$ Microsporidia was not reported in this study since Calcoflour White Staining which requires demanding laboratory set up ${ }^{15}$ was not applied.

However, use of ART is associated with parasite clearance and marked reduction in AIDS related morbidity and mortality ${ }^{45}$ and it is supposed to provide psychological support to PLHA. ${ }^{23}$ IPI was insignificantly higher in ART naive patients than in On ART patients. Similar result was found in Ethiopia. ${ }^{33}$ Poor living condition, lower $\mathrm{CD}_{4}$ T-cell counts, having contact with animal and using unprotected water for drinking are other factors accompanying IPI among HIV/AIDS patients. ${ }^{7}$ Though the ART does not seem successful for significant reduction of intestinal parasitic infections, initiation of ART only after patients declining to threshold of $\mathrm{CD}_{4}$ T-cell counts $<500 / \mu \mathrm{l},{ }^{41}$ might have caused its less impact, since it was to apply just after confirmation of HIV cases as per WHO guidelines. ${ }^{46}$

Diarrhoea was found significantly associated with IPI among PLHA corresponding to previous study. ${ }^{4,26} 24.3 \%$ prevalence of poly parasitic infection in PLHA was higher than that reported by previous study. ${ }^{14,25}$ It is associated 
with severe immune status of PLHA which can't completely clear even single parasite from body. ${ }^{38}$

\section{CONCLUSIONS}

The higher prevalence of opportunistic protozoa among PLHA indicates the need of routine parasite investigation using sensitive methods so that it will be helpful for the proper therapeutic managements.

\section{List of abbreviations used}

IPI, Intestinal Parasitic Infection; PLHA, People Living with HIV/AIDS; GI, Gastrointestinal; OR, Odds ratio; $\mathrm{CI}$, Confidence Interval.

\section{DECLARATIONS}

\section{Ethical clearance and consent to participate}

Study was approved by Ethical Review Board of Nepal Health Research Council (Reg. no. 191/2016). Informed consent was taken from participant. Patients diagnosed as being infected with intestinal parasites were referred appropriately for treatment.

\section{Consent for publications \\ Not applicable}

\section{Availability of data and materials}

The datasets (and or materials) used and or analysed during the current study are available from the corresponding author on reasonable request.

\section{Competing interests}

This article was the part of Master Thesis of Homa Nath Sharma, which was supervised by Anjana Singh, Bimal Sharma Chalise and Ganesh Rai and helped by Nabaraj Adhikari and Anup Bastola. All authors declare that they have no competing interests.

\section{Funding}

University Grants Commission (UGC), Nepal had provided Master Thesis Preparation Support 2016. But UGC was not involved in study design, collection, analysis and interpretation of data, writing manuscript and decision to publish the research article.

\section{ACKNOWLEDGEMENTS}

Firstly, we would like to acknowledge patients for their voluntary participation in this research. It gives us pleasure to acknowledge Prof. Dr. Shiva Kumar Rai, Dr. Megha Raj Banjara, Dr. Ramesh Kumar Kharel and Mr. Yadav Baral for their indispensable help in different steps of this research.

\section{REFERENCES}

1. Paul M and Beatrice H. Origin of HIV and AIDS pandemic. Cold Spring Harb Perspect Med J 2011; 1:a006841.

2. Akinbo FO, Omoregie R, Eromwon R, Ignenimah $I O$ and Airueghiomon V. Prevalence of intestinal parasites among patients of a tertiary hospital in Benin city Nigeria. N Am J Med Sci 2011; 3:462-364.

3. Abaver DT, Nwobegahay JM, Goon DT, Iweriebor BC and Ange DN. Prevalence of intestinal parasitic infection among HIV/ AIDS patients from two health institutions in Abuja, Nigeria. J Afr Health Sci 2011; 11:524-527.

4. Tiwari BR, Ghimire P, Malla S, Sharma B and Karki S. Intestinal parasitic infection among the HIV infected patients in Nepal. The Journal of infection in developing countries 2013;7:550-555.

5. Shilpa HS and Mariraj J. Intestinal parasitic infection in relation to HIV/AIDS status, Diarrhea and CD4 T cell counts. Int J Curr Microbiol App Sci 2016; 5:523-531.

6. Kelly P. Diarrhea and AIDS: recent developments in African setting. Afr Health 1998; 20:16-18.

7. Alemu F. Prevalence of intestinal parasites and other parasites among HIVIAIDS patients with on ART attending Dilla Referral Hospital, Ethiopia. J AIDS Clin Res 2014; 5:343.

8. Morris A, Lundgren JD, Masur H, Walzer PD, Hanson DL, Frederick $\mathrm{T}$, et al. Current epidemiology of Pneumocystis Pneumonia. Emerg Infect Dis 2004;10:1713-1720.

9. National center for AIDS and SID control (NCASC). Factsheet 2: Cumulative HIV cases in Nepal, as of Asar 2073 (July 2016). Kathmandu: Government of Nepal, NCASC;2016. Accessed date: July 2016.Available from: URL: http://www.ncasc.gov. np/uploaded/facts_n_figure/2016_factsheet_2_reported/HIV_ Cases_2016_pdf.

10. National center for AIDS and SID control (NCASC). Factsheet 6 : HIV care and Antiretroviral Therapy (ART) service in Nepal, as of July 2016. Kathmandu: Government of Nepal, NCASC; 2016. Accessed date: July 2016. Available from: URL: http://www. ncasc.gov.np/uploaded/facts_n_figure/2016_factsheet_6_HIV_ Care_ART_service_in_Nepal_2016_pdf.

11. Singh GK, Parajuli KP, Shrestha M, Pandey S and Yadav SC. The prevalence of intestinal parasitic infestation in a tertiary care hospital: A retrospective study. Journal of Nobel Medical College 2011; 2:13-17.

12. Yadav $\mathrm{K}$ and Prakash $\mathrm{S}$. Study of intestinal parasitosis among school children of Kathmandu Valley Nepal. Asian Journal of Biomedical and Pharmaceutical Sciences 2016; 6:40.

13. Khanal LK, Rai SK, Khanal PR and Ghimire G. Status of intestinal parasitosis among hospital visiting patients in Deukhury Valley Dang, Nepal. Nepal Medical Coll J 2011; 13:100-102.

14. Adhikari NA, Rai SK, Singh A, Dahal S and Ghimire G. Intestinal parasitic infections among HIV seropositive and high risk group subjects for HIV infection in Nepal. Nepal Med Coll J 2006;8:166-170.

15. Baveja CP, Baveja V. Medical parasitology. $2^{\text {nd }}$ ed. New Delhi: Arya Publishing Company; 2011, pp 201-223.

16. Sah RB, Bhattaral S, Yadav S, Baral R, Jha N and Pokhrel PK. A study of intestinal parasites and associated risk factors among the school children of Itahari, Eastern region of Nepal. Trop Parasitol 2013; 3:140-144.

17. Agrawal PK, Rai SK, Khanal LK, Ghimire G, Banjara MR and Singh A. Intestinal parasitic infections among patients attending Nepal Medical College Teaching Hospital, Kathmandu, Nepal. Nepal Med Coll J 2012; 14:80-83.

18. Kunwar R, Acharya $L$ and Karki $S$. Decreasing prevalence of intestinal parasitic infection among school aged children in 
Nepal: A systematic review and meta analysis. Trans R Soc Trop Med Hyg 2016; 110:324-332.

19. Mehraj V, Hatcher J, Akhtar S, Rafique $G$ and Beg MA. Prevalence and factors associated with intestinal parasitic infection among children in an urban slum of Karachi. PLOS ONE. 2008; 3:e3680.

20. Abate A, Kibret B, Bekalu E, Abera S, Teklu T, Yalew A, et al. A cross sectional study on the prevalence of intestinal parasites and associated risk factors in Tedu Health Centre, Ethiopia. ISRN parasitology. 2013:757451.

21. Duedu KO, Karikari YA, Attah SK and Ayeh-Kumi PF. Prevalence of intestinal parasites among patients of a Ghanian Psychiatry hospital. BMC Research Notes 2015; 8:651.

22. Dalela G and Vijaya A. Prevalence of intestinal parasitic infection among HIV infected patients at SRG hospital, Jhalawar, India. Int J Curr Microbiol App Sci 2015; 4:817-824.

23. Wasti SP, Simkhada $P$ and Van TE. Antiretroviral Therapy Programme in Nepal: Problems and barriers. Kathmandu University Medical Journal 2009;7:27.

24. Jaiswal S, Sharma S, Bhat SR, Pokhrel T, Chaudhary N and Sharma I. Distribution of intestinal parasite in people living with HIVIAIDS of different care centre of Pokhara Valley, Nepal. Sch J App Med Sci 2014; 2:3366-3369.

25. Ghimire A, Bhandari S, Tandukar S, Amatya J, Bhandari D and Sherchand JB. Enteric parasitic infection among HIV infected patients visiting Tribhuvan University Teaching Hospital, Nepal. BMC Res Notes 2016; 9:204-207.

26. Sherchand JB, Ohora H, Sakurada S, Basnet A, Tandukar S, Sherchand JB, et al. Enteric opportunistic parasitic infection Among HIV seropositive patients in Kathmandu Nepal. Kathmandu University Medical School 2012; 11:14-17.

27. Dwivedi, L. Prevalence of opportunistic intestinal parasite infection in HIV position population of central India region. South Asian Journal of experimental Biology 2013; 4:15-23.

28. Mahmud MA, Bezabih AM and Gebru RB. Risk factors for intestinal parasitosis among antiretroviral treated HIVIAIDS patients in Ethiopia. International Journal of STD and AIDS. 2014; 25:778-784.

29. Nsagha DS, Njunda AL, Assob NJC, Ayima CW, Tenue EA, Kibu OD and Kwenti TE. Intestinal parasitic infection in relation to CD4 T cell counts and diarrhoea in HIVIAIDS patients with or without antiretroviral therapy in Cameroon. BMC Infectious Disease. 2016; 16:9-12.

30. Amancio FAM, Pascoto VM, Sowja LR, Calvie SA and Pereira PCM. Intestinal parasitic infection in HIVIAIDS patients of Brazil. J Venom Anim Toxins incl Trop Dis 2012; 18.

31. Jegede EF, Oyeyi ET, Bichi AH, Mbah HA and Torpey K. Prevalence of intestinal parasites among HIVIAIDS patients attending infectious disease hospital, Kano, Nigeria. Pan Afr Med J 2014; 17:295.

32. Sapkota DA, Ghimire PA and Manandhar S. Entericparasitois in patients with HIV infection and AIDS in Nepal. J Nepal Health Res Counc 2004; 2:1-5.
33. Kiros H, Nibret E, Munshea A, Kerisew B and Adal M. Prevalence of intestinal protozoan infection among individual living with HIVIAIDS at Felegehiwot Referral hospital, Bahir Dar, Ethiopia. International Journal of infectious disease 2015; 35:80-86.

34. Opara KN, Udoidung NI, Opara DC, Okon OE, Edosomwan EU and Udoh AJ. The impact of Intestinal Parasitic Infection on the nutritional status of rural and urban school aged children in Nigeria. Int J MCH AIDS 2012; 1:73-82.

35. Shelton AA. Sexually transmitted parasitic diseases. Clin Colon Rectal Surg 2004; 17:231-234.

36. Agholi M, Hatam GR and Motazedian MH. HIV/AIDS-Associated Opportunistic Protozoal Diarrhea. AIDS Res Hum Retroviruses 2013; 29:35-41.

37. Vyas N, Sood S, Sharma B and Kumar M. The prevalence of intestinal parasitic infection and the related profile of the CD4 count in HIVIAIDS people with diarrhoea in Jaipur City. Journal of Clinical and Diagnostic Research 2013; 7:454-456.

38. Amatya R, Shreshtha R, Poudel $\mathrm{N}$ and Bhandari S. Opportunistic intestinal parasites and CD4 counts in HIV infected people. Journal of pathology of Nepal 2011; 1:118-121.

39. Venkatesh NR, Ravi Chandra Prakash H, Ukey PM, Vijayanath V, Shreeharsha G and Chandak VK. Opportunistic intestinal parasitic infection in HIVIAIDS patients presenting with diarrhoea and their correlation with CD4 T lymphocytes counts. Int J Pharm Bio Sci 2012; 2:293-299.

40. Sangani GS, Minjalali H, Farnia S and Rezaeian M. Prevalence of intestinal coccidial infections among different groups of immunecompromised patients. Iran J Parasitol 2016; 1:332-338.

41. National center for AIDS and SID control (NCASC). National Consolidated Guidelines for treating and preventing HIV in Nepal 2014. Kathmandu: Government of Nepal, NCASC; 2014. Accessed date: Nov 7 2014. Available from: URL: http://www. ncasc.gov.np/Uploaded_National_Consolidated_Guidelines_ for_treating_n_preventing_HIV_in_Nepal_2014_pdf.

42. Dehovitz JA, Pape JW, Boncy M and Johnson WD. Clinical manifestation and therapy of isospora belli infection in AIDS. N Engl J Med 1986;315:87-90.

43. Verdier RI, Fitzgerald DW, Johnson WD and Pape JW. Trimethoprim-sulfamethoxazole compared with ciprofloxacin for treatment and prophylaxis of Isospora beli and Cyclospora cayetanensis infection in HIV-infected patients: a randomized, controlled trial. Ann Intern Med 2000; 132:885-888.

44. Massoud NM, Said DE and El-Salamouny. Prevalence of Cyclospora cayetnensis among symptomatic and asymptomatic immune-competent children less than five years of age in Alexandria, Egypt. Alexandria Journal of Medicine 2012;48:251-259

45. Pozio EG and Morales MA. The impact of HIV-protease inhibitors on opportunistic parasites. Trends Parasitol 2005; 21:58-63.

46. World Health Organization (WHO). Guidelines on when to start antiretroviral therapy and on pre-exposure prophylaxis for HIV. Sep 30 2015. Available from: URL: http://www.who.int/hiv/pub/ guidelines/en.

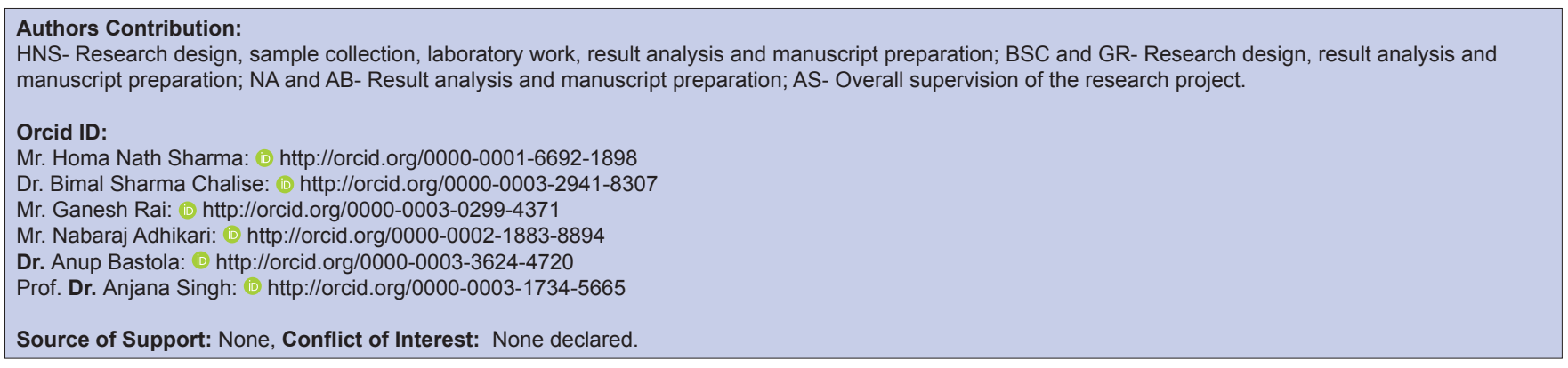

